\title{
Automated Control Of Aspiration Of Explosion-And Fire-Hazardous Industries With Filters-Dust Collectors
}

\author{
${ }^{1}$ Romanyuk E.V., ${ }^{2}$ Fedorov A.V., ${ }^{3}$ Holostov A.L., ${ }^{4}$ Denisov A.N.
}

${ }^{1}$ Ph.D., Academy of State Fire Service of the Ministry of Emergency Situations of Russia

${ }^{2}$ Doctor of Technical Sciences, Professor, Academy of State Fire Service of the Ministry of Emergency Situations of Russia

${ }^{3}$ Doctor of Technical Sciences, Academy of State Fire Service of the Ministry of Emergency Situations of Russia

${ }^{4}$ Doctor of Technical Sciences Professor, State Fire Service Academy of the Ministry of Emergencies of Russia

1'scercso@mail.ru, ${ }^{2}$ fedorov-ppa@yandex.ru, ${ }^{3}$ holostov@mail.ru, ${ }^{4}$ dan_aleks@mail.ru

Article History: Received: 11 January 2021; Accepted: 27 February 2021; Published online: 5 April 2021

\begin{abstract}
The article presents a scheme for automated control of an aspiration system equipped with filters-dust collectors for production associated with the circulation of explosive dust- gas flows. As an indicator of the state of the entire aspiration, it is proposed to use the total pressure drop on the filter partition and the temperature shown by the pressure sensors. Based on the experimental study of the unrelated layer structure filter total pressure drop dynamics a mathematical description, algorithm and software for trouble-free operation of aspiration were obtained.
\end{abstract}

Keywords: filter, authorization, control, aspiration, explosive, pressure drop.

\section{Introduction}

The efficiency and safety of industries where dust is circulated associated with the functioning of the aspiration system. A common solution for collecting dust in such systems are dust filters, which differ in the variety of materials and designs used. When working with explosive dust and gas streams, the best option are dust filters with granular loading. The state of the filter-dust collector determines the state of aspiration, therefore the monitoring of this system is based primarily on the assessment of the state of the filter. The existing methods for controlling the operation of aspiration are mainly associated with adjusting the air flow rate, which implies maintaining a vacuum in the manifold; maintaining the differential pressure (air velocity); simultaneous maintenance of vacuum in the manifold and maintenance of air velocity in the transport pipeline, etc[1-3]. Taking into account the specifics of the operation of granular filters, these methods may be unprofitable, since they consume significant energy resources of the enterprise. The use of a granular filter loading with an unbound structure opens up a number of new possibilities in determining the control method, namely, the use of the filter itself as a control mechanism. This method requires a theoretical basis in the field of monitoring the operation of filters, especially in emergency mode.The foregoing served as a prerequisite for conducting experiments, evaluating their results and creating on their basis new methods of controlling the operation of the filter and aspiration as a whole, including in emergency modes.

\section{Theoretical justification and problem statement}

Working with explosive dust and gas flows typical for food, chemical, woodworking, textile industries [4] requires not only maintaining sufficient efficiency, but also increased reliability, which is achieved by using a two-level control system. Despite the fact that the data taken into account for dust collection by filters is very wide, it can be sufficient to control and correct the process using the total pressure drop across the filters [2-3, 56]. To provide fire protection, air temperature data are used, which can be obtained from pressure sensors. The data exchange diagram and control actions in the automated control system are shown in Fig. 1.

The diagram shows three levels of an automated system. The lower level includes a local ACS, an automated fire warning system (AFWS) and an automated fire protection system (AFPS). The local ACS is designed to receive and process data on the pressure before and after the filter, as well as the air temperature in the filter and the aspiration system as a whole. This system calculates the total pressure drop and, based on it, determines the need for filter regeneration, or a layer change if regeneration is ineffective. The ACS has control actions: it turns off the fan, opens and closes the dampers, turns on the receiver, the timer and other devices that depend on the regeneration method.

An AFWS is designed to operate in situations that are borderline with emergency, for example, lack of regeneration with a long constant total pressure drop. Controlling influences here can be directed both at the executive mechanisms and at informing the system of a higher level. 


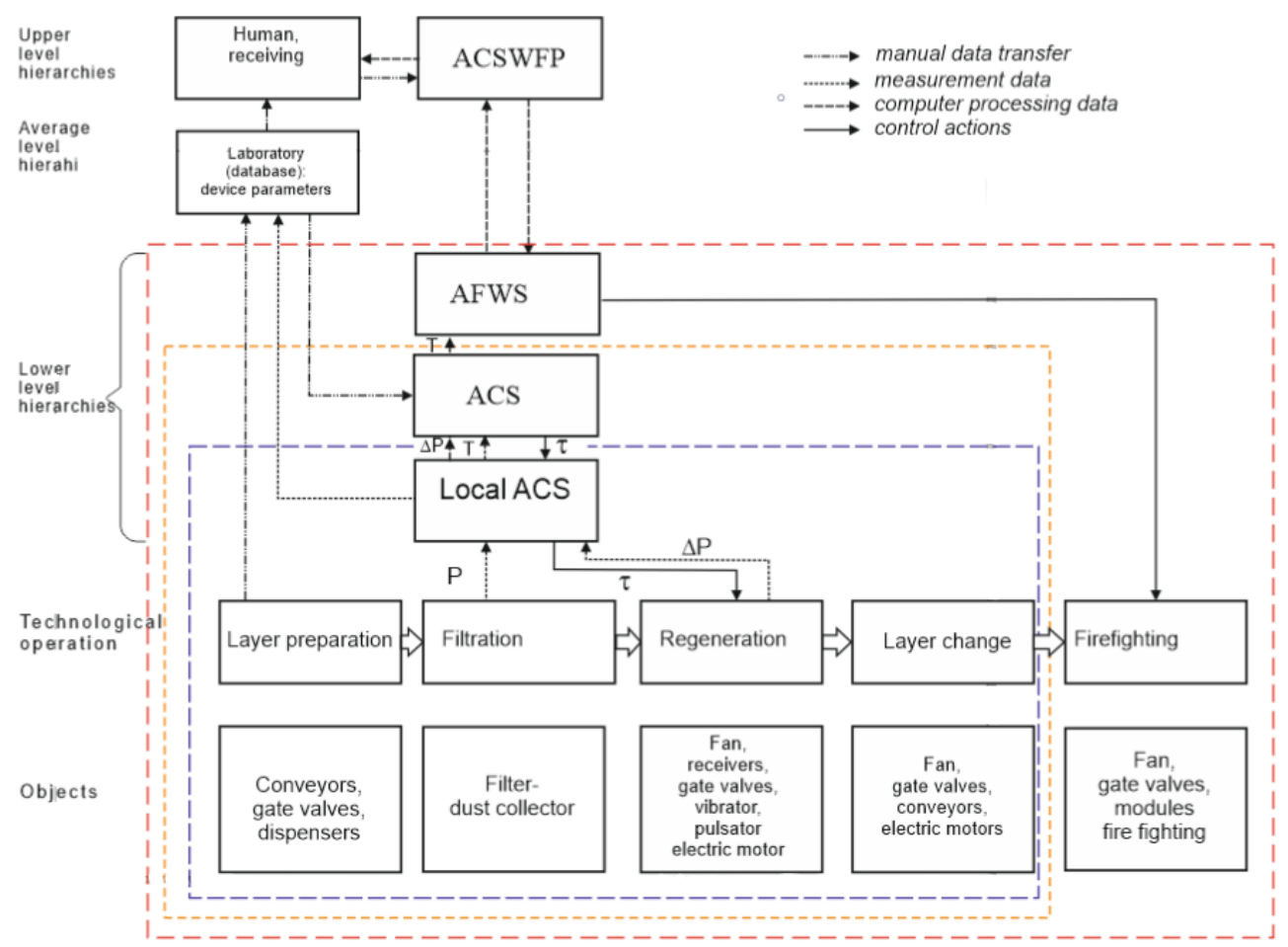

Fig. 1. Data exchange scheme and control actions

The functions of the AFPS are manifested when the temperature in the system reaches above normal for a given technological process. Its control actions are aimed at turning off the draft device (fan), switching valves, turning on fire extinguishing modules.

The middle level of the hierarchy of the system is a database management system, the function of which is to collect information about the parameters of the filtering medium and dust and gas flow, transfer data to AFWS, and collect data from the ACS. The automated control, warning and fire protection system (AFPS) receives data from the lower levels, organizes and transmits, if necessary, to a person. Filter operation involves several modes of its operation. In the literature, two modes are considered: filtration and regeneration, which does not take into account all the features and control capabilities, as well as a clear definition of the emergency mode of the filter and all aspiration as a whole. Automation of work requires a detailed experimental assessment of the filter and a corresponding set of criteria and mathematical dependencies.

\section{Experimental research}

The purpose of the experimental research was to study the dynamics of the basic indicator of the filter operation - the total pressure drop and its use in the control system. The pressure sensors used in the experiments made it possible not only to record the change in the total pressure drop, but also the temperature up to $60^{\circ} \mathrm{C}$. This made it possible to use the same sensors to trigger the fire protection system for flows with normal temperature (10-40 ${ }^{\circ} \mathrm{C}$ ). During the experiments, materials of various origins and properties (gravel, polymer granules, peas, grain, millet, etc.) were used as granular filter materials. However, the base ideal layer was taken to be metal balls $4 \cdot 10^{-}$ ${ }^{3} \mathrm{~m}$ in size, having a spherical shape.

The obtained experimental data made it possible to reveal the general nature of the change in the total pressure drop across the filters under study, including during operation in emergency mode (reaching clogging of the filter partition), which can be characterized by the generalized diagram shown in Fig. 2.

According to the diagram, two emergency operating modes can be defined:

1) "Blockage" mode associated with clogging of the filter partition and previously described in the literature [2-6].

2) Mode "Exostion" (from the English word "exorcise" - to expel, release), associated with the gradual pulling out of fine particles from the structure of the layer and the occurrence of an explosive concentration of dust from the purified air. Thismodehasnotbeenpreviouslystudied. 


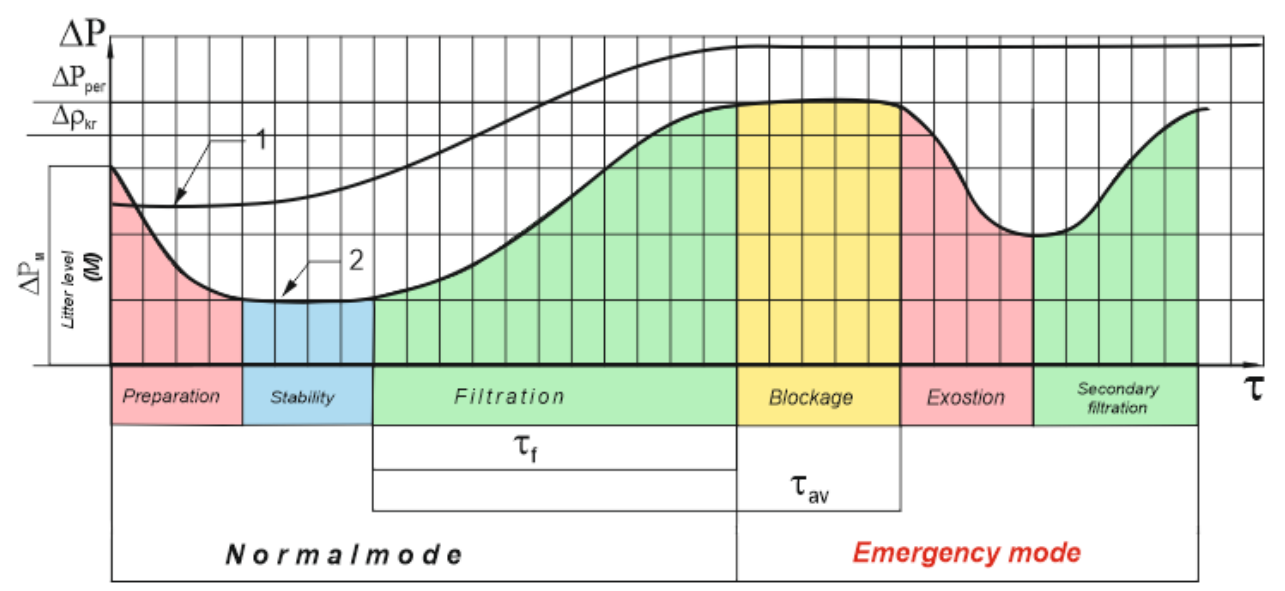

Figure: 2. Scheme of changes in the total pressure drop across granular filters: 1 - curve reflecting traditional ideas about the nature of the change; 2 - obtained on the basis of experimental data.

The second mode takes place with ineffective aspiration control and is often the cause of industrial accidents, therefore, its occurrence in the system should be assessed and predicted [8].

When assessing the emergency operation of the system, namely the "Blockage" and "Exostion" modes and their subsequent control, it is important to prevent the emergency state, and therefore to determine the pre-emergency state. The criterion for signaling a certain action to protect the system will be the time it takes to reach a certain system state. In emergency control, this is a pre-emergency state corresponding to the "Exostion" mode.

\section{Mathematical processing}

According to numerous studies in the field of filtration, the total pressure drop across the filtering baffle $(\Delta P)$ depends on many parameters: the duration of filtration $(\tau)$, the height of the filter layer $(h)$, the diameter of the equivalent pore space $\left(d_{e}\right)$ and others [4]. By the method of expert assessments and subsequent a priori ranking, the most priority ones for an ideal layer of metal balls were identified. Having limited the set of input and determined variables by this method, the dependence of the filtering duration on the input parameters for the considered type of filters will have the general form

$\tau=f\left(h, d_{e}, \Delta P\right)$.

(1)

Taking this into account, we will evaluate the moment for the system operation using two introduced criteria - a dimensionless complex $\mathrm{K}$ and a filtration rate $\mathrm{T}$, which allow taking into account or measuring the influencing parameters.

The dimensionless criterion will be determined by the formula

$K=\frac{1000 \cdot \Delta P_{i n} \cdot \tau \cdot d_{e}^{2}}{m \cdot w}$,

where $\Delta P_{i n}-$ initial total pressure drop across the filter bed, $\mathrm{Pa} ; \tau$ - filtration duration, $\mathrm{s} ; d_{e}$ - diameter equivalent to the pore space of a granular layer with an unbound structure, $\mathrm{m} ; w-$ dust and gas flow rate, $\mathrm{m} / \mathrm{s} ; m-$ weight of clean filter bed, $\mathrm{kg}$. Table 1 shows the calculation for the experimental filter layers of their metal balls.

Table 1 - Calculation of $\mathrm{K}$ for experimental ideal layers

\begin{tabular}{|l|l|l|l|l|l|l|l|}
\hline № & $\begin{array}{l}\text { Filterlayerhei } \\
\text { ght, } \mathrm{m}\end{array}$ & $\begin{array}{l}\text { Initial pressure } \\
\text { drop across the } \\
\text { filter bed } \Delta \mathrm{P}_{\mathrm{H}}, \\
\mathrm{Pa}\end{array}$ & $\begin{array}{l}\text { Filtermass } \\
\mathrm{m}, \mathrm{kg}\end{array}$ & $\begin{array}{l}\text { Diameter } \\
\text { equivalent } \\
\text { taped pore } \\
\text { space de, } \mathrm{m}\end{array}$ & $\begin{array}{l}\text { Dust speed } \\
\text { gas flow at } \\
\text { the filter } \\
\text { inlet w, } \\
\mathrm{m} / \mathrm{s}\end{array}$ & $\begin{array}{l}\text { Continued } \\
\text { live } \\
\text { filtration } \\
\text { efficiency } \\
\mathrm{s}\end{array}$ & $\mathrm{K}$, \\
\hline 1. & 0,01 & 18 & 0,7 & 0,001 & 4 & 10000 & 64 \\
\hline 2. & 0,02 & 30 & 1,4 & 0,001 & 4 & 10000 & 54 \\
\hline 3. & 0,03 & 25 & 2,08 & 0,001 & 4 & 10000 & 30 \\
\hline 4. & 0,04 & 120 & 2,77 & 0,001 & 4 & 10000 & 108 \\
\hline
\end{tabular}




\section{AUTOMATED CONTROL OF ASPIRATION OF EXPLOSION-AND FIRE-HAZARDOUS INDUSTRIES WITH FILTERS-DUST COLLECTORS}

Exostion mode in a given time interval corresponding to the beginning of dust breakthrough will be observed for an ideal layer at $K \approx 30$. When changing the diameter of the grains of the bulk material, the area of the filtering material or the dispersion of dust, in order to obtain the corresponding value of $\mathrm{K}$, the remaining variables included in the formula (2).

The rate of filtration is determined by the current readings of the sensors using the formula

$T=\frac{\Delta^{2} P}{\Delta \tau}$,

where $T$ - rate of rise of pressure difference, $\mathrm{Pa} / \mathrm{s} ; \tau$ - filtration time, $\mathrm{s} ; \mathrm{P}$ - pressure, $\mathrm{Pa}$. As a result of processing the experimental data, the values of the filtration rate were obtained, presented in the table 2 .

Table 2 - results of processing experimental data

\begin{tabular}{|l|l|l|l|l|}
\hline \multirow{3}{*}{ Time, s } & \multicolumn{3}{|l|}{$\begin{array}{l}\text { Filtering layer with parameters: } \mathrm{h}=0,04 \mathrm{~m}, \\
\mathrm{~d}_{\mathrm{e}}=2.5 \cdot 10^{-3} \mathrm{~m}\end{array}$} & \multicolumn{2}{l}{$\begin{array}{l}\text { Filter layer with parameters: } \\
\mathrm{h}=0,03 \mathrm{~m}, \mathrm{~d}_{\mathrm{e}}=2,5 \cdot 10^{-3} \mathrm{~m}\end{array}$} \\
\cline { 2 - 5 } & Differentialpressure, $\mathrm{Pa}$ & Temp T & Differentialpressure, Pa & Temp T \\
\hline 350 & & & & \\
\hline 680 & 300 & 0,06 & 35 & - \\
\hline 1000 & 320 & 0,03 & 60 & 0,71 \\
\hline 1330 & 330 & 0,03 & 110 & 0,83 \\
\hline 1660 & 340 & 0,03 & 160 & 0,45 \\
\hline 1990 & 350 & 0,02 & 200 & 0,25 \\
\hline 2320 & 357 & 0,04 & 220 & 0,1 \\
\hline 2650 & 370 & 0,01 & 245 & 0,11 \\
\hline 2980 & 375 & 0,005 & 255 & 0,04 \\
\hline 3310 & 377 & 0,007 & 275 & 0,06 \\
\hline 3640 & 380 & 0,005 & 280 & 0,02 \\
\hline 3970 & 382 & $-0,01$ & 300 & 0,07 \\
\hline 4300 & 380 & 0 & 298 & $-0,01$ \\
\hline 4630 & 380 & 0 & 280 & $-0,06$ \\
\hline 4960 & 380 & 0 & 292 & 0,02 \\
\hline 5290 & 380 & 0 & 280 & $-0,04$ \\
\hline 5620 & 380 & 0 & 280 & 0 \\
\hline 5950 & 380 & 0 & 275 & $-0,02$ \\
\hline 6280 & 380 & 0 & 275 & 0 \\
\hline 6610 & 380 & 0 & 260 & $-0,05$ \\
\hline & 380 & 0 & 250 & $-0,04$ \\
\hline
\end{tabular}

At $\mathrm{T}=0$, the filter becomes clogged. When the rate of $\mathrm{T}$ values is less than 0 for the period $\tau_{2}-\tau_{1}$ (in this case, the rate exceeds $1,9 \%$, since according to the experimental data $\mathrm{T}=0,005-0,007$ is considered due to the measurement error, which is approximately $1,9 \%$ of the total changes in the pressure drop), one should talk about the occurrence of an exostion mode.

To evaluate the operation of real filtering layers made of granular material, it is also advisable to use the proposed formulas (2) and (3), however, one should take into account the period of preparation of the layer for filtration, which is largely associated with the deviation of the grain shape from ideal and the presence of initial dustiness ("littersize"). Empirical studies have shown that filtering layers made of natural materials are characterized by such phenomena as dust collection due to electrostatic forces arising during the dust collection process; drop in the total pressure drop at the beginning of the process, associated with drying of the material [8] in an upward air flow, drop in the total pressure drop due to blowing out of the initial dust content. The drying process plays an important role for thin filter layers and causes a drop in the total pressure drop, however, the largest contribution to the initial drop is made by the process of removal of its own dust of the used imperfect layers.

The initial pressure drop due to dust removal changes the character of the process curve - the "Preparation" mode appears - Fig.2. This mode affects the explosive state of the aspiration system, therefore, this effect should be taken into account when developing the mathematical and algorithmic support of the ACS.

In order to assess the initial state of various real layers, we will introduce a point estimate from 1 to 10 for each of the indicated materials for such parameters as the grain shape of the layer, size and initial dustiness.

The shape was evaluated from 1 to 10: from irregular to regular spherical. It is also proposed to evaluate the grain size of the filter layer, designated S, from 1 to 10 points: from coarse to finer. 
The assessment of litter size, designated $\mathrm{M}$, is carried out by the content of its own dust in the filter material at the time of the start of filtration. For 1 point, the content of more than $20 \%$ of dust from the mass of the material is taken and 10 points - its almost complete absence.

The coefficient we need is found by the formula

$$
E=\frac{F \cdot S \cdot M}{F_{\max } \cdot S_{\max } \cdot M_{\max }},
$$

where $F, F_{\max }-$ determined and maximum possible point estimate of the grain shape of the filter layer, respectively; $S, S_{\max }$ - determined and maximum possible point estimate of the grain size of the filter layer, respectively; $M, M_{\max }$ - determined and maximum possible score assessment of the filter layer contamination. It should also be taken into account that the duration of the preparation period of the granular layer will also be influenced by its height or volume, therefore it is advisable to use the specific coefficient $\mathrm{E}_{\mathrm{ud}}$, taken equal to the coefficient $\mathrm{E}$, and referred to $1 \cdot 10^{-2} \mathrm{~m}^{3}$ of the volume of the granular layer.

Table 3 shows the dependence of the preparation period for imperfect granular layers of millet on the coefficient E, obtained on the basis of processing experimental.

Table 3. - Results of processing experimental data.

\begin{tabular}{|c|c|c|c|c|c|}
\hline № & Filterlayermaterial & $\begin{array}{l}\text { Layervolume, } \\
\mathrm{m}^{3}\end{array}$ & Specificcoefficient $E_{u d}$ & $\begin{array}{rr}\text { Coefficient } & \begin{array}{r}E \\
\mathrm{~m}^{-3}\end{array} \\
\end{array}$ & $\begin{array}{l}\text { Duration of the } \\
\text { preparation period, } s\end{array}$ \\
\hline 1. & Millet & 2,46 & 0,1 & 0,246 & 1000 \\
\hline 2. & Millet & 3,69 & 0,1 & 0,369 & 1800 \\
\hline 3. & Millet & 4,92 & 0,1 & 0,492 & 2100 \\
\hline 4 & Millet & 7,38 & 0,1 & 0,738 & 2200 \\
\hline 5 & Millet & 13,53 & 0,1 & 1,353 & - \\
\hline
\end{tabular}

As can be seen from table 3, the duration of the preparation period has a non-linear dependence on the coefficient $\mathrm{E}$ and the layer height. The result of data processing using Microsoft Excel is shown in Fig. 3.

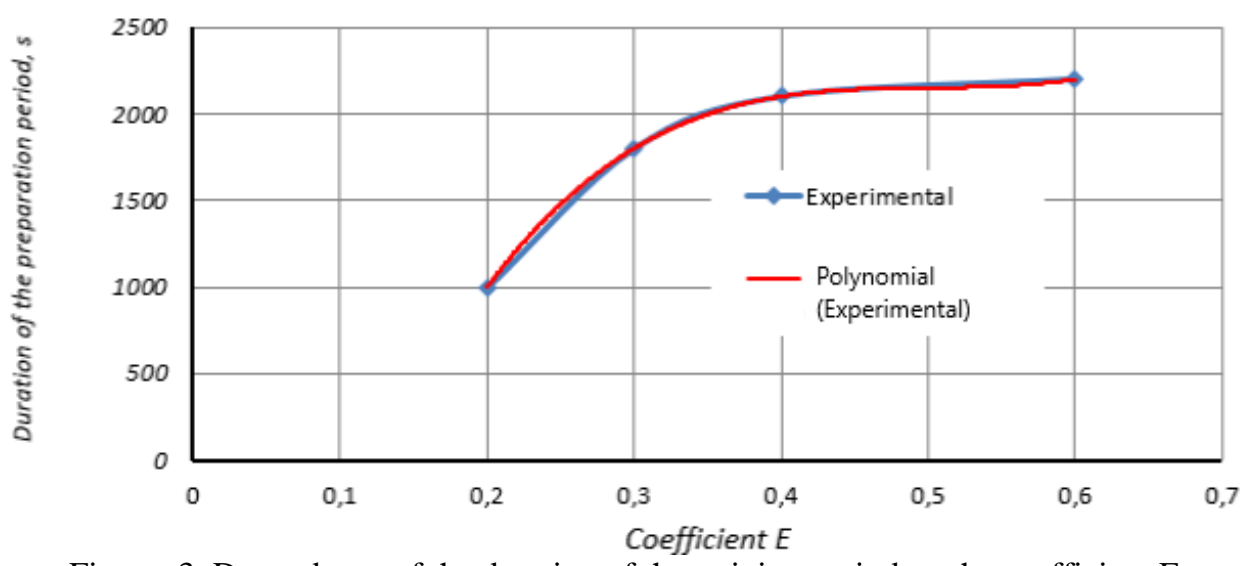

Figure: 3. Dependence of the duration of the training period on the coefficient E.

After processing and approximation, the following regression equation is obtained, which makes it possible to determine the duration of the period of preparation of the layer for filtration:

$\tau_{\text {prep }}=22391 E^{3}-41311 E^{2}+25474 E-3100$.

4)

When the monitoring system is operating, the number of measurements required to identify the time of preparation of the layer for filtration should be determined. During the experiments, the interval between measurements was 10 seconds, so the number of measurements will be equal

$$
\begin{gathered}
t=\tau_{\text {prep }} / \tau_{10}=\left(22391 E^{3}-41311 E^{2}+25474 E-3100\right) / 10= \\
2239,1 E^{3}-4131,1 E^{2}+2547,4 E-310
\end{gathered} .
$$

(5)

During the period of preparation of the layer, dust is emitted from the side of the cleaned air, therefore, this air should be avoided into closed volumes of production equipment and premises or this period should be excluded from the working cycle of the dust collector.

Table 4 shows the parameters of the imperfect filter layer (millet) used in the experiments and the corresponding $\mathrm{K}$ values. 
AUTOMATED CONTROL OF ASPIRATION OF EXPLOSION-AND FIRE-HAZARDOUS INDUSTRIES WITH FILTERS-DUST COLLECTORS

Table 4 - Calculation of $\mathrm{K}$ for experimental non-ideal layers (millet)

\begin{tabular}{|l|l|l|l|l|l|l|l|}
\hline $\begin{array}{r}\text { № } \\
\Pi / \Pi\end{array}$ & $\begin{array}{l}\text { Filterlay } \\
\text { erheight, } \\
\mathrm{m}\end{array}$ & $\begin{array}{l}\text { Initial pressure drop } \\
\text { across the filtering } \\
\text { layer } \Delta \mathrm{P}_{\text {in }}, \mathrm{Pa}\end{array}$ & $\begin{array}{l}\text { Filterma } \\
\text { ss m, kg }\end{array}$ & $\begin{array}{l}\text { Diameter } \\
\text { equivalent } \\
\text { taped pore space } \\
\mathrm{de}_{\mathrm{e}}, \mathrm{m}\end{array}$ & $\begin{array}{l}\text { Dust speed } \\
\text { gas flow at } \\
\text { the filter inlet } \\
\mathrm{w}, \\
\mathrm{m} / \mathrm{s}\end{array}$ & $\begin{array}{l}\text { Continued } \\
\text { live } \\
\text { filtration } \\
\text { efficiency } \\
\tau, \mathrm{s}\end{array}$ & $\mathrm{K}$ \\
\hline 1. & 0,02 & 7 & 0,1848 & 0,0006 & 4 & 10000 & 34 \\
\hline 2. & 0,03 & 20 & 0,2772 & 0,0006 & 4 & 10000 & 65 \\
\hline 3. & 0,04 & 35 & 0,3696 & 0,0006 & 4 & 10000 & 85 \\
\hline 4. & 0,05 & 50 & 0,462 & 0,0006 & 4 & 10000 & 97 \\
\hline
\end{tabular}

For the indicated filtration duration $\tau=10000 \mathrm{~s}$, the "Exostion" mode occurs only for a layer with a height of $0,02 \mathrm{~m}$, for others this mode arises with a longer filtration. For an imperfect filter layer with a height of $0,02 \mathrm{~m}$, the dimensionless criterion $\mathrm{K}$ is 34 .

\section{Algorithm and software}

An algorithm that takes into account the preparation period, as well as determines the onset of emergency modes using the proposed formulas, is shown in Fig. 4. If the drop in the total pressure drop after changing the layer continues for more than the calculated time period $(t)$, then the further course of the process is not only ineffective, but can also lead to the release of a significant amount of dust ("Preparation" mode, Fig. 3), therefore during this period, the dust-air stream should not be discharged into the production area, or should be disposed of. However, in the considered intervalthe dust emission does not reach a concentration higher than the lower concentration limit of flame propagation (LCRP), at which the ignition of the dust-air flow is possible.The particles and conglomerates blown out in this process are deposited in the aspiration lines. In both cases, technical solutions can be proposed to prevent the concentration of dust in the form of an airgel and/or air injection in closed production volumes. 


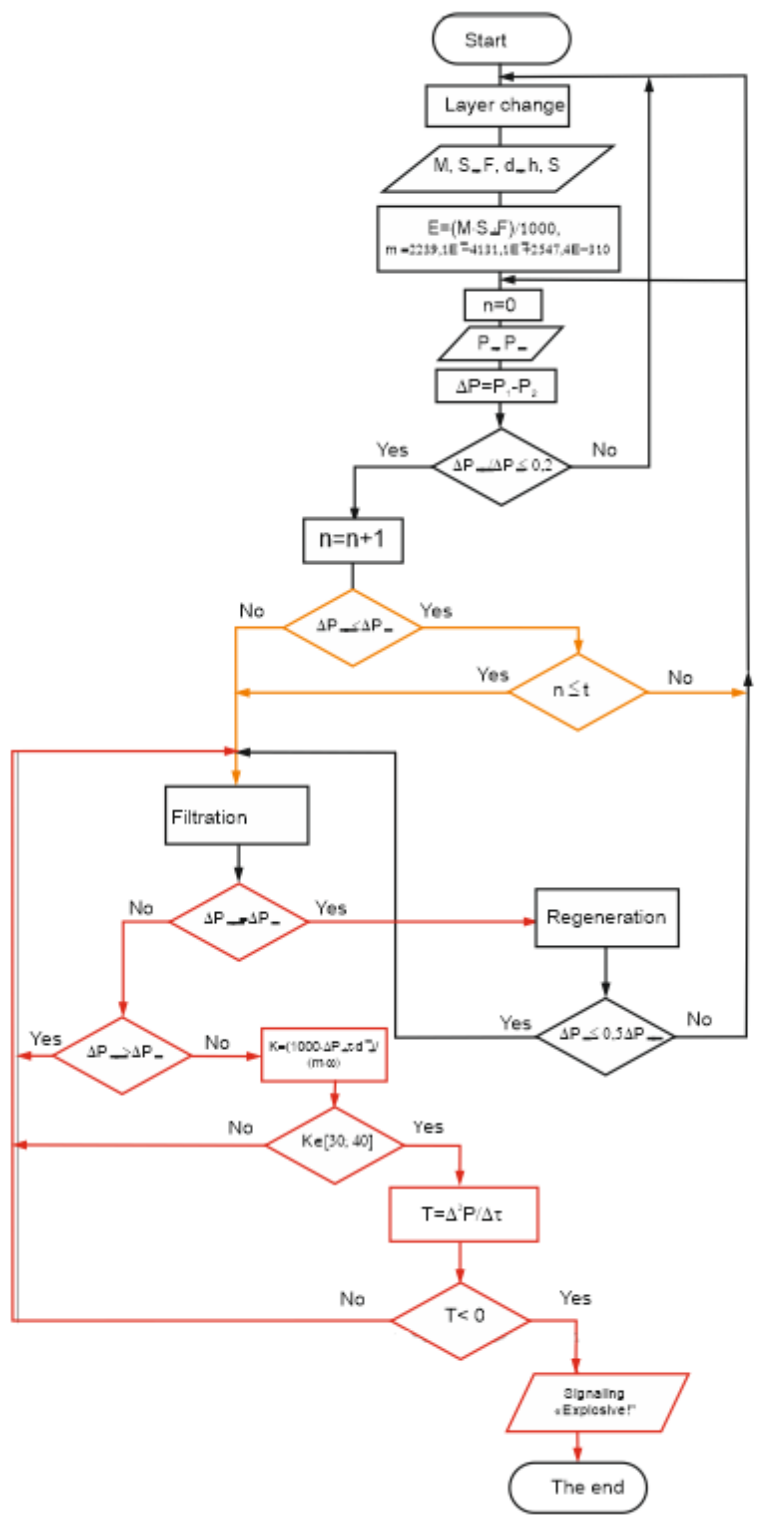

Figure: 4. Block diagram of filter operation modes control.

Shown in fig. 4Algorithm, using formulas (1-4), determines the possibility of the onset of the explosion hazard mode, taking into account the parameters of the layer, and also identifies the onset of this mode by the current readings of the pressure sensors. When calculating the dimensionless criterion $\mathrm{K}$, an error is allowed $10 \%$.

The same algorithm determines the need for regeneration and layer change. Block "Signal" Explosive! " is the starting point for regulating the system in order to withdraw from this mode.

To implement the developed technique, illustrated using the block diagram in Fig. 5, a software product was developed, the windows of which are shown in Fig. 6 [9] 


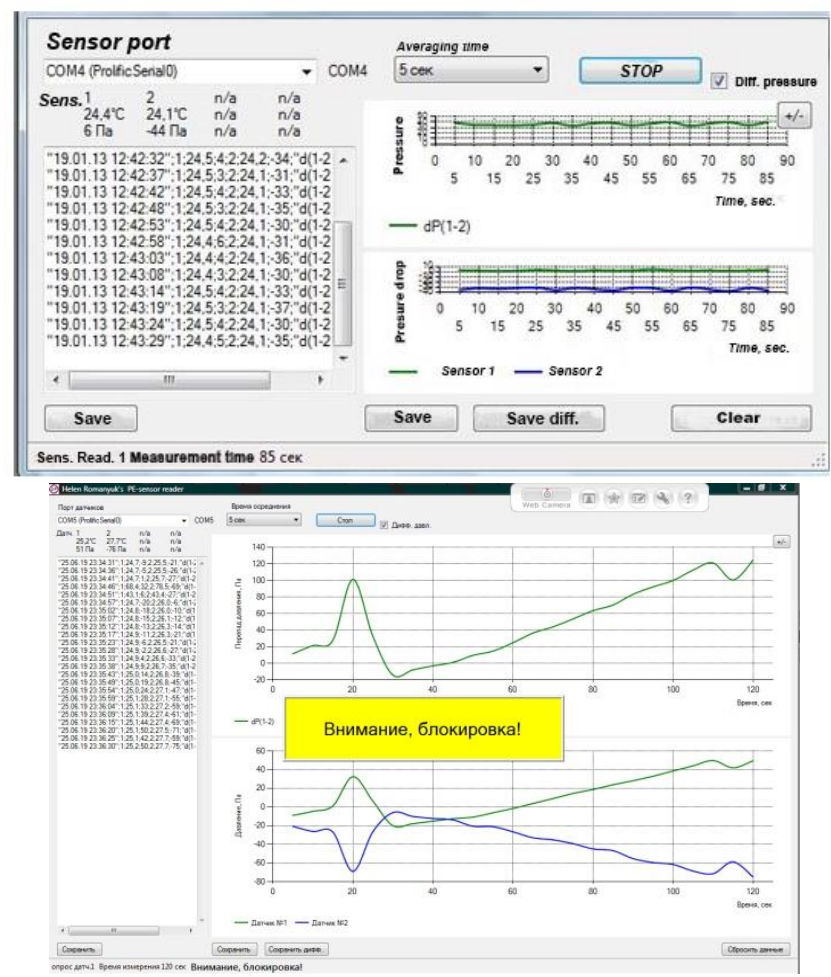

Fig. 5. Software windows.

The program provides the following functions: reading the current readings of two measuring channels from sensors that support the ModBus RTU exchange protocol; logging of the received data with their subsequent saving in CSV format; calculation of the difference in values between the readings of any two connected sensors; visualization of the obtained and calculated values in the form of graphs with the possibility of saving them in a graphic file; signaling of mode change to the display unit and duplication using the windows that appear on the computer monitor.

\section{Conclusion}

The methods obtained and the algorithms and software created on their basis allow automating the operation of not only a granular filter-dust collector with different types of loading, but also filters with a related structure, for example, fibrous, since fiber filters are widely used in many areas of industry and construction. However, it is granular filters that are the best option for cleaning explosive streams with combustible dust.

Industrial granular filters have a very narrow use due to the complexity of operation, which in turn is associated with the lack of information about the specifics of the process. The experiments carried out and the revealed modes allow correct operation of the aspiration systems and automate the control over them. The mobility of the filter layer makes it possible to use it to implement control actions on the entire aspiration system. To implement such effects by manipulating the filter layer, new filter designs have been developed [10-11] and there are already known models [4-5].

The implementation of measures for the use of granular filters in combination with an automation system allows you to reduce the cost of fire-prevention measures in production, to comply with environmental and labor protection standards.

\section{References}

1. Mody V., Jakhiste R. Dust control handbook. New Jersey: Noyes Publications, 1988. 205 p.

2. Topcheyev YU.I. Atlas dlyaproyektirovaniyasistemavtomaticheskogoregulirovaniya. M.: Mashinostroyeniye, 1989. $752 \mathrm{~s}$.

3. Barton J. Dust Explosion Prevention and Protection: A Practical Guide. Elsevier Science, 2002. 300 s.

4. Krasovitskiy YU. V., Durov V. V. Obespylivaniyegazovzernistymisloyami. YU. V. Krasovitskiy. M.: Khimiya, 1991. - 192 s.

5. Krasovitskiy YU. V., Romanyuk Ye. V., Chugunova I. A., Fedorova M. N. Kombinirovannyyefil'troval'nyyestrukturydlyavysokoeffektivnogopyleulavlivaniya Stroitel'nyyematerialy. 2009. № 9. S. 70-71.

6. Shihang Li, Fei Wang, Jie Xin, Biao Xie, Shuda Hu, HaoJin, Fubao Zhou. Study on effects of particle size and maximum pressure drop on the filtration and pulse-jet cleaning performance of pleated cartridge filter // Process Safety and Environmental Protectio, 2019. Volume 123. P. 99-104. 
7. RomanyukYe.V., Fedorov A.V. Osobennostiavtomatizatsiisistemaspiratsii s zernistymifil'trami // Avtomatizatsiya v promyshlennosti. 2019. № 8. S. 61-66.

8. Ostrikov A.N., Kalashnikov G.V., Shevtsov S.A Osnovnyyezakonomernostiteplo- i massoobmena v protsessesushkipishchevogorastitel'nogosyr'ya Pishchevayatekhnologiya. 2014. № 4 (340). S. 87-92.

9. RomanyukYe.V. Monitoring rabotyfil'tra-pyleulovitelya: svidetel'stvo o gosudarstvennoyregistratsii RF programmydlya EVM № 2020612201; zayavl. 4.02.2020; opubl. 19.02.2020.

10. Nasypnoykombinirovannyyfil'trpatentnaizobreteniye № 2474463. / Ye.V. Romanyuk, YU.V. Krasovitskiy, I.A. Chugunova. - № 2474463; zayavl. 27.09.2011; opubl. 10.02.2013. - Byul. № 4.

11. Nasypnoykombinirovannyyfil'tr s sistemoyregeneratsii : pat. № 2629683 Ros. Federatsiya: MPK 51 V01V 53/00, VO1V 24/04 / Ye.V. Romanyuk, M.A. Pinayev; zayavitel' ipatentoobladatel': Ye.V. Romanyuk. - № 2629683; zayavl. 29.09.2015; opubl. 31.08.2017. - Byul. № 25. 